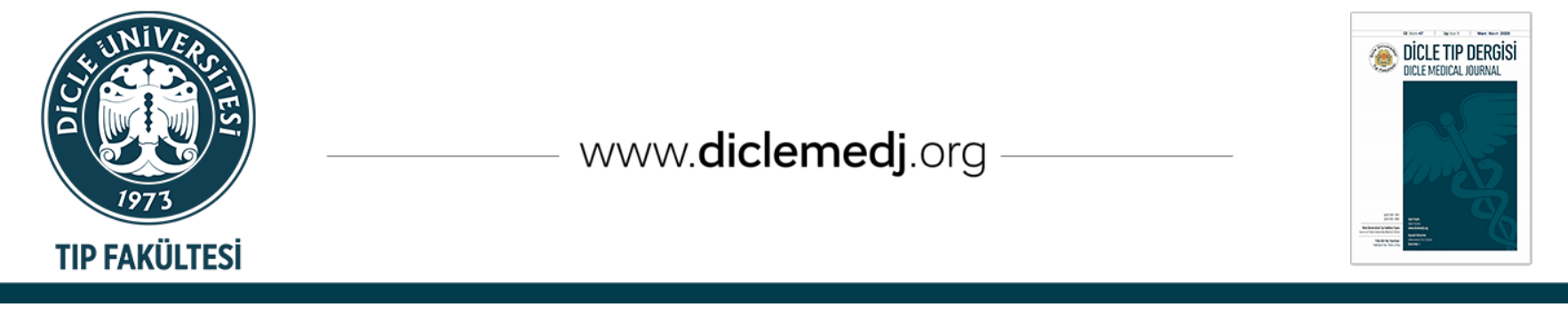

Original Article / Özgün Araştırma

\title{
New Screening Method For Cervical Cancer- Polar Probe
}

\author{
Halis Özdemir iD 1, Gonca Çoban Şerbetçioğlu iD 2, Ali Ayhan (iD 2 \\ 1 Department of Obstetrics, Gynecology \& Reproductive Sciences, Gazi University Ankara, Turkey \\ 2 Department of Obstetrics, Gynecology \& Reproductive Sciences, Başkent University Ankara, Turkey \\ Received: 06.05.2020; Revised: 06.07.2020; Accepted: 07.07.2020
}

\begin{abstract}
Objective: Although extensive screening methods had been developed, cervical cancer remains to be an essential health problem. Early detection and administration of appropriate therapy is still a lifesaving procedure, especially for cervical cancer. The most common screening method for cervical cancer is still the cervical cytology (Pap-test). We aim to find out the advantages and disadvantages of a recently developed method, which is called as Polar Probe.

Methods: Two different approaches had been used (conventional Pap test and Polar Probe), and 1438 patients were included in the study. Of these, 819 had been screened with Polar Probe. All eligible patients were firstly screened using Polar Probe and then using the Pap test. Each patient with an abnormal Polar Probe result was referred to colposcopy room, where she was re-evaluated using colposcopy.
\end{abstract}

Results: The rate of abnormal smear result was $1.04 \%$, and the corresponding percentage was calculated as $0.62 \%$ in LSIL, $0.34 \%$ in ASCUS, and $0.069 \%$ in HSIL. A total of 819 patients underwent Polar Probe, and the results were abnormal in 261 patients and normal in 558 patients. Abnormality rate was 1\% in Pap test and 31.9\% in Polar Probe. Although the positive predictive value was $27 \%$ for Polar Probe test and $16 \%$ for Pap test, as the colposcopy was indicated only for the patients with abnormal results in Polar Probe. The need for colposcopy dramatically increased with the use of Polar Probe.

Conclusion: Use of Polar Probe alone was not found to be cost effective. Combination with other methods of screening would decrease the cost of the process.

Keywords: Polar Probe, Pap test, pre-invasive cervical lesion.

\section{DOI: 10.5798/dicletip.799883}

Correspondence / Yazışma Adresi: Halis Ozdemir, Ergazi Mh. Batı Bulvari (Boulevard) Nevadium Residences $109 \mathrm{~b} / 116$ Yenimahalle/Ankara, Turkey e-mail: drhalisozdemir@gmail.com 


\section{Servikal Kanser İçin Yeni Tarama Metodu- Polar Probe}

Öz

Amaç: Kapsamlı tarama yöntemleri geliştirilmiş olmasına rağmen, rahim ağzı kanseri temel bir sağlık sorunu olmaya devam etmektedir. Uygun tedavinin erken tespiti ve uygulanması, özellikle serviks kanseri için hala hayat kurtarıcı bir prosedürdür. Serviks kanseri için en yaygın tarama yöntemi servikal sitolojidir (Pap-testi). Bu çalışmada Polar Probe adı verilen ve yeni geliştirilen bir tarama yöntemin etkinliğini test ettik.

Yöntemler: İki farklı yaklaşım kullanıldı (geleneksel Pap testi ve Polar Probe) ve çalışmaya 1438 hasta dahil edildi. Bu hastalardan 819 tanesi Polar Probe ile de tarandı. Tüm uygun hastalar önce Polar Probe ve ardından Pap testi kullanılarak tarandı. Anormal bir Polar Probe sonucu olan her hasta kolposkopi odasına yönlendirildi ve burada kolposkopi cihazı kullanılarak hastalar yeniden değerlendirildi.

Bulgular: Anormal smear sonucunun oranı \%1,04 idi ve ilgili yüzde LSIL'de \%0,62, ASCUS'ta \%0,34 ve HSIL'de \%0,069 olarak hesaplandı. Toplam 819 hastaya Polar Probe uygulandı ve sonuçlar 261 hastada anormal ve 558 hastada normaldi. Anormallik oranı Pap testinde \%1 ve Polar Probe \%31,9 idi. Pozitif prediktif değer Polar Probe testi için \%27 ve Pap testi için \%16'idi. Kolposkopi sadece Polar Probe'da anormal sonuçları olan hastalarında yapıldı. Bu çalışmada Polar Probe kullanımıyla kolposkopi ihtiyacı önemli ölçüde artmıştır.

Sonuç: Sadece Polar Probe kullanımını kolposkopi gerekliliği nedeniyle maliyeti artırmaktadır. Diğer tarama yöntemleri ile kombinasyon, işlemin maliyetini düşürebilir.

Anahtar kelimeler: Polar Probe, Pap testi, pre-invaziv servikal lezyon.

\section{INTRODUCTION}

Cervical cancer is one of the leading causes of cancer-related deaths in women worldwide. In the 1930s, cervical cancer was the leading cause of cancer-related deaths in the USA. Although cytological screening decreased these deaths by $70 \%$, cervical cancer remains to be among the first three leading cause of cancer-related deaths in women worldwide. Based on Globocan 2018 data, cervical cancer is the 3rd prominent women's cancer in worldwide, and 569.847 new cases annually occurs, and within the same year, 311.365 cases die. This number is mostly due to the cases occurring in developing countries ${ }^{1}$. In our country, the incidence in women is $4.3 / 100.000$ and the mortality rate is $1.7 / 100.000^{2}$.

Although the mean age at the diagnosis of cervical cancer is 52 years, its incidence peaks between the ages of 35 and 39 years and between the ages of 60 and 64 years. Cervical carcinoma in situ (CIS) is seen 10 years earlier, which corresponds to the ages of 35-40 years, than cervical cancer. Low-grade cervical lesions are detected approximately between the ages of 26-30 years, which corresponding to detection at an earlier age compared to CIS $^{3}$. Dysplasias are the precursor lesions of cervical cancer and, if left untreated, some of them will progress to cancer ${ }^{4}$. It is observed that, annually, half of the patients diagnosed with cervical cancer had not had an early diagnosis due to either low coverage of the Pap smear test or the low diagnostic capacity of Pap smear test. Therefore, alternative methods for cervical cancer screening come up.

For the conventional Pap test, a wide sensitivity range was given in high-grade lesions $30 \%$ 87\%) American College of and Gynecologists ${ }^{5}$. Also, a false negativity rate ranging between $14 \%$ and $33 \%$ was given 6 . For these reasons, screening utilizing elective strategies came up. TruScreen (Polarntechnics Limited, Sydney, Australia), which is one of the devices produced for this purpose, has been firstly accredited in 2003. The response that the tissues are giving according to low-dose electrical pulsation was digitalized and is express as "normal" or 
"abnormal" upon the comparison done with the results of various cervical tissues previously memorized in the device. The device uses a combination of biosensors, including directly reflected light, backscattered light, and electrical decay curves. The tissue is illuminated at four discrete wavelengths in the visible and infrared regions of the spectrum. The information is filtered, sampled, and processed by a microcomputer within a portable console to extract the parameters of the highest value for tissue discrimination ${ }^{7}$.

Fricke and Morse firstly suggested that the hypothesis that the resistance of the tissues against the electrical current was different in 1926 with a study for breast cancer. After that, in 1949, Langman and Burr discovered that cancerous and noncancerous cervical tissues had different electrical parameters. Indeed, the performance of the test in vivo was not possible in that period, because the equipment was not appropriate. However, over the last decades, technological advances made this technology more applicable.

In this study, we investigated the efficacy of the screening using Polar Probe (TruScreen) in our patient population.

\section{METHOD}

\section{Patient selection}

After the approval of Baskent University Hospital, Ethics Board (project number KA09/159), three contiguous districts with similar characteristics were considered to be eligible for this screening (Anamur, Bozyazi, and Aydincik). These three districts are both economically and socially identical. In some parts of all three regions, there were difficulties of health services access due to low socioeconomic status. Each admitting patient was enrolled in the study if fulfilling the inclusion criteria.

\section{Criteria for Pap test are as follow}

- Having turned 20 years old or at least 3 years after the first sexual intercourse.

- The absence of a previous hysterectomy due to the benign reason (The patients who were not known to have a benign reason or who reported to have never had Pap test underwent a Pap test but were not included in the study.)

- Absence of a Pap test within the last year.

Polar Probe (TruScreen) criteria

- Signed informed consent,

- Age between 18 and 70-years-old

- Absence of a Pap smear within the last 6 weeks

- Absence of heavy bleeding during the procedure

- Absence of pregnancy or having passed more than 4 months since the last delivery

- Absence of the previous hysterectomy

- Absence of cervical surgery within the last three months

- Absence of a known photosensitive disease

- Absence of prior radiotherapy on the pelvic area

- Chemotherapy-naïve or absence of chemotherapy within the previous five weeks

- Eligible for Pap test

Each patient was examined in the rooms designed for TruScreen and Pap test and colposcopy and small surgical interventions. In each room, TruScreen device was used by a physician, nurse, or technician, whereas the physicians applied colposcopy.

All eligible patients were firstly screened using TruScreen and then using the Pap test. Each patient with an abnormal TruScreen result was referred to colposcopy room, where she was reevaluated using colposcopy.

\section{Evaluation Using TruScreen}


A speculum of appropriate size was inserted and positioned to leave the cervix in the midline. In the patients with very thick mucus, the mucus was removed using a ring forceps and gauze without touching the cervix. TruScreen device was calibrated using a specially designed optical test plug after ensuring that the device was open and that the printer had enough paper. After the calibration, a single use sensor (SUS) was connected to the device. The sensor of the equipment was moved across appropriate points on the cervical transformation zone. At the end of the screening, a print-out was taken automatically by the device or by pushing to a button. Patient information and TruScreen result were registered in the patient registration form and, if the result was abnormal, the patient was sent to colposcopy room.

\section{Smear Sample Collection}

Conventional Pap test and two different smear brushes were used. In the patients in whom the endocervical canal cannot be visualized, the smear sample was collected using endocervical smear brush.

\section{Colposcopic Evaluation}

Each patient with an abnormal TruScreen result underwent colposcopy. For colposcopy, two different devices were used at different time points. In the district of Anamur, digital colposcopy (Centrel S1 Grimed) device was used. In the regions of Bozyazi and Aydincik, classic colposcopy (colposcopy F1 Grimed) device was used. Following the preparation of the patient, acetic acid 3\% and iodine solution were administered to the cervix, and biopsy specimens were collected from the areas with abnormal appearance using biopsy forceps.

\section{Evaluation Of Pap Test And Biopsy}

Pap test and biopsy results were evaluated in 2 different centers. Mersin KETEM evaluated paptest slides. Biopsy specimens were evaluated by
Onay Laboratory of Pathology and Cytology (Ankara). Each center evaluated the samples without knowing the result of the other center.

\section{Statistical Analysis}

Study data were analyzed using SPSS version 17.0 statistical package software) (Statistical Package for the Social Sciences, version 17.0, SPSS Inc, Chicago, III, USA). Comparative data were analyzed using a Chi-Square test. Statistical significance level was considered to be $\mathrm{p}<0.05$.

\section{RESULTS}

In a total of 3 districts, 1438 patients were screened, and 819 patients underwent TruScreen. Statistical analysis was performed on 819 patients (cytological abnormality rate was expressed based on the total number of patients). The demografic characteristics of the regions were given in Table 1.

Table I: The demographic characteristics of the regions

\begin{tabular}{|l|l|l|l|l|}
\hline & Anamur & Bozyazi & Aydincik & Total \\
\hline Age & $42,5 \pm 8,7$ & $43,7 \pm 9,8$ & $41,3 \pm 8,4$ & $42,5 \pm 9,04$ \\
\hline Premenopausal & $263(72 \%)$ & $160(70 \%)$ & $177(76 \%)$ & $600(73 \%)$ \\
\hline Vaginal discharge & $153(42 \%)$ & $132(58 \%)$ & $180(77 \%)$ & $465(56 \%)$ \\
\hline $\begin{array}{l}\text { Postcoital } \\
\text { bleeding }\end{array}$ & $38(10 \%)$ & $16(7 \%)$ & $7(3 \%)$ & $61(7.5 \%)$ \\
\hline $\begin{array}{l}\text { Previously } \\
\text { existing pap test }\end{array}$ & $42(11 \%)$ & $22(9 \%)$ & $9(3.8 \%)$ & $73(8.9 \%)$ \\
\hline $\begin{array}{l}\text { Pap-test applied } \\
697\end{array}$ & 361 & 225 & 367 & 1438 \\
\hline $\begin{array}{l}\text { Truscreen } \\
\text { applied }\end{array}$ & 125 & 75 & 64 & 818 \\
\hline $\begin{array}{l}\text { Colposcopy } \\
\text { applied }\end{array}$ & 87 & 59 & 264 & 197 \\
\hline \begin{tabular}{l} 
Biopsy was taken \\
\hline
\end{tabular}
\end{tabular}

A total of 1438 patients had a Pap test. In all three districts, a total number of abnormal Pap test results was 15 and, of these, 5 were defined as ASCUS, 9 as LSIL and 1 as HSIL. The rate of abnormal smear result was $1.04 \%$, and the corresponding percentage was calculated as $0.62 \%$ in LSIL, $0.34 \%$ in ASCUS, and $0.069 \%$ in 
HSIL. ASC-H and AGC cell was not reported for any of the three districts.

A total of 819 patients underwent TruScreen, and the results were abnormal in 261 patients and normal in 558 patients. All of the patients with abnormal TruScreen result underwent colposcopy. Six patients with normal TruScreen results additionally underwent a colposcopy, one due to smear result showing ASCUS and 5 dues to the presence of clinical suspicion of the low-grade lesion. A total of 267 patients underwent colposcopy. Of these patients, 197 underwent biopsy concomitantly to colposcopy. A total of 242 biopsy sample were collected and evaluated. Seventy-one patients underwent colposcopy alone and did not undergo biopsy because of the absence of a pathological appearance.

Biopsy results of a total of 197 patients are given in Table 2. Three patients had a high-grade lesion, and 7 patients had a low-grade lesion. However, when condyloma and koilocytic changes were considered to be abnormal, the total number of histologic abnormalities was 55 (55/197; 27.9\%). Most commonly observed histopathologic result was chronic cervicitis (122/197; 61.9\%).

Table II: Cervical biopsy results of participants

\begin{tabular}{|l|l|}
\hline Histopathological results & Number \\
\hline High-grade lesion & 3 \\
\hline Low-grade lesion & 7 \\
\hline Condyloma (flat and verrucous) & 25 \\
\hline Koilocytic change & 20 \\
\hline Immature squamous metaplasia & 1 \\
\hline Chronic cervicitis & 122 \\
\hline Normal epithelial & 11 \\
\hline Nabothian cyst & 8 \\
\hline
\end{tabular}

Of 15 patients with cytological abnormalities, 8 underwent TruScreen, and its results are given in Table 3. As 4 patients with cytological abnormality showed normal TruScreen results, they did not undergo colposcopy at that moment. However, Patient 3 was called for the next screening and re-evaluated. Patient 5 admitted to our clinic by herself and was taken to close monitoring. Colposcopy and biopsy that we performed in our clinic resulted in the highgrade lesion. The patients with a biopsy result equal to or greater than CIN1 are listed in Table 3. Biopsy result and smear result were correlated in none of the patients, except in Patient 8 (Ş.D.).

Table III: Cytology Results compare with Truscreen and biopsy

\begin{tabular}{|l|l|l|l|}
\hline $\begin{array}{l}\text { Patients } \\
\text { number }\end{array}$ & $\begin{array}{l}\text { Cytology } \\
\text { Results }\end{array}$ & TruScreen results & Biopsy results \\
\hline 1 T.E. & ASCUS & Normal & No biopsy \\
\hline 2 Ü.Y. & ASCUS & Abnormal & Chronic cervicitis \\
\hline 3 H.K. & ASCUS & Normal & Chronic cervicitis \\
\hline 4 K.B. & LSIL & Normal & No biopsy \\
\hline 5 A.G. & LSIL & Normal & HSIL \\
\hline 6 S.G. & LSIL & Abnormal & Chronic cervicitis \\
\hline 7 A.S & LSIL & Abnormal & Chronic cervicitis \\
\hline 8 Ş.D. & HSIL & Abnormal & HSIL \\
\hline 9 H.D. & Normal* & Abnormal & HSIL \\
\hline 10 F.B. & Normal* & Abnormal & LSIL \\
\hline 11 H.Y. & Normal* & Abnormal & LSIL \\
\hline 12 H.K. & Normal* & Abnormal & LSIL \\
\hline 13 A.Ç. & Normal* & Abnormal & LSIL \\
\hline 14 M.G. & Normal* & Abnormal & LSIL \\
\hline 15 A.Ö. & Normal* & Abnormal & LSIL \\
\hline 16 A.Ş. & Normal* & Abnormal & LSIL \\
\hline * Malignancy and intraepithelial lesions were not observed \\
\hline
\end{tabular}

Abnormality rate was 1\% in Pap test and 31.9\% in TruScreen (table 4). When these patients were evaluated using colposcopy, half of the patients showed eventual low-grade or highgrade lesions. However, when these patients were assessed using biopsy, only $28 \%$ showed abnormal histology. 
Table IV: Abnormality Rates

\begin{tabular}{|l|l|l|l|}
\hline & Normal (\%) & Abnormal & Total \\
\hline Pap-Test & $802(97.9 \%)$ & $8(1 \%)$ & $819^{* * *}$ \\
\hline TruScreen & $557(68 \%)$ & $261(31.9)$ & 819 \\
\hline Colposcopy & $126(47 \%)$ & $138(53 \%)$ & 264 \\
\hline Cervical biopsy & $142(72 \%)$ & $55(28 \%)$ & 197 \\
\hline
\end{tabular}

*9 patients' pap-test were result as degenerate

** 1 patient has insufficient pap-test results

As seen in Table 5, only 4 of the patients who showed abnormal results with TruScreen were found to have epithelial cell abnormality using the Pap test. On the other hand, 254 of 258 patients who were found to be abnormal based on TruScreen test were reported to be normal using the Pap test. Compare results of TruScreen, colposcopy and Pap test with biopsy results were given at Table 6 .

Table V: Compare the results of Truscreen and pap-test

\begin{tabular}{|l|l|l|l|}
\hline \multicolumn{3}{|l|}{ Truscreen } & total(n) \\
\hline Pap Test & Abnormal(n) & Normal(n) & \\
\hline Abnormal (n) & 4 & 4 & 8 \\
\hline Normal (n) & 254 & 547 & 809 \\
\hline Total (n) & 258 & 551 & 809 \\
\hline
\end{tabular}

Table VI: Compare results of TruScreen, colposcopy and Pap test with biopsy results

\begin{tabular}{|l|l|l|}
\hline \multirow{2}{*}{} & \multicolumn{2}{|l|}{ Abnormal histology } \\
\cline { 2 - 3 } & Positive ( $\mathrm{n})$ & Negative $(\mathrm{n})$ \\
\hline TruScreen (n) & & \\
\hline Positive & 53 & 137 \\
\hline Negative & 1 & 5 \\
\hline Colposcopy (n) & & \\
\hline Positive & 47 & 91 \\
\hline Negative & 8 & 51 \\
\hline Pap Test (n) & & \\
\hline Positive & 2 & 4 \\
\hline Negative & 52 & 136 \\
\hline
\end{tabular}

Although the positive predictive value was $27 \%$ for TruScreen test and 16\% for Pap test, as the colposcopy was indicated only for the patients with abnormal results in TruScreen in our group, the sensitivity and specificity of this test would not be accurate. For colposcopy, the sensitivity was $85 \%$, and the specificity was $35 \%$. The positive predictive value was $35 \%$ in the patients who underwent colposcopy.

Among the patients who were screened using TruScreen, 35 had minor bleeding, 1 had significant bleeding, and 1 had minor discomfort. There is no statistical significance between TruScreen operator and the complication $(\mathrm{p}=.112)$, but abnormal TruScreen rates were significantly lower if TruScreen operator was a doctor ( $\mathrm{p}$.001). However, no statistical significance was found between the number of spots examined and the abnormal result $(\mathrm{p}=.598)$.

\section{DISCUSSION}

For the screening for cervical cancer, the use of a less demanding test with a higher accuracy rate has always been needed. Upon the introduction of the conventional Pap test in 1941 and the efficient use of colposcopy in the 1960s, the incidence and the mortality of cervical cancer showed a substantial drop. In our study abnormality rate was $1 \%$ in Pap test and $31.9 \%$ in TruScreen. The positive predictive value was $27 \%$ for TruScreen test and $16 \%$ for Pap test. The need for colposcopy dramatically increased with the use of TruScreen.

Given that the efficacy of the cervical cytology screening varied by laboratory conditions, it is indispensable that alternatives of this inert program always appear. The coming up of alternative TruScreen test is the result of these reasons.

Potential advantages of the screening with TruScreen are as follows: TruScreen test is the first objective, that is not required to be interpreted. The results are expressed as "normal" or "abnormal" and each patient with an abnormal result proceeds to the next test. Another advantage of the test is that the 
declaration of the result does not require additional time. Therefore, patient satisfaction is maximal. Although the population to be screened is invited in advance in the community-based screening strategy, based on opportunistic approach, this is on own initiative of the patients. The patients who immediately learn the result will have higher satisfaction, increasing the rate of participation in the screening program. In the study performed by Mould T AJ et al. ${ }^{8}$, the questionnaire done by 152 patients revealed that the patients experienced less anxiety ( $2 / 10$ vs. $4.5 / 10)$, less pain ( $3 \%$ vs. $33 \%$ ) and less bleeding and discomfort (5\% vs. $12 \%$ ) with Polarprobe. As a result, the majority of the women preferred Polarprobe to smear test $(82 \%$ vs. $2 \%)$. In our study, the complication rate was $4.6 \%$, and all but one of these complications was minor bleeding or minor discomfort.

The disadvantages of TruScreen include being affected by any tissue abnormality. Chronic cervicitis is a quite common pathology, and despite its benign nature, it is misinterpreted by TruScreen, giving an abnormal result. Another disadvantage of TruScreen is regarding its safety. A device that is not well-prepared will give an abnormal result. Its reasons include the calibration of the equipment, the cleanliness of the probe end, and whether the disposable end used is broken. There is no method to analyze whether the abnormally reported result is due to the perception of the tissue as "abnormal" or due to the device. Therefore, the safety range of the device is quite narrow.

Although the ability to detect the abnormal tissue using electrical current has been discovered in the 1990s, this method has not been introduced in the routine practice, and there is a limited number on literature concerning it, leading to biggest handicaps of this method.

Based on the literature (Table 7) 4,7,9-13, the first study for Polarprobe was published by $\mathrm{M}$.
Coppleson et al. in 19949. This study was conducted on 183 patients, and the results obtained with Polarprobe and colposcopy/histology were given. In this study, the accuracy rate was detected to be $85 \%$ in the patients who were known to be histologically low-grade, $90 \%$ in high-grade lesions, and 99\% in invasive cancers. However, the first patientto-patient clinical study was performed by Singer A et al. in 199710. In this study, the patients were classified into two groups. While Group 1 included 41 patients with cervical carcinoma at various stages with the symptomatic and visible lesion, Group 2 included 45 patients who had not undergone cervical surgery within the last 12 months and who had negative results of both Pap test and colposcopy. In the patients with histologically confirmed cervical carcinoma, Polarprobe method was found to have a sensitivity of $98 \%$ and a specificity of $91 \%$. In the study of Singer, A et al., which was conducted on a total of 651 patients from 10 centers and published in $2003,{ }^{7}$ the researchers reported the sensitivity of TruScreen, Pap Test and the combination of these two tests. Two different categories of patients were enrolled in the study. The first group included only the volunteers $(n=485)$ and the second group included the patients who admitted to a colposcopy clinic for a previously known abnormal result. The prevalence rates of CIN1 and CIN2-3 were $1 \%$ and $0.6 \%$ in the first group and $14 \%$ and $31 \%$ in the second group, respectively. In this study, the sensitivity of TruScreen for CIN2/3 and CIN3 was calculated as $70 \%$ and $67 \%$, respectively, and the specificity as $81 \%$. In this study, for Pap test and combined test (TruScreen + Pap Test), the sensitivity was reported to be $69 \%$ and $93 \%$ for CIN $2 / 3$ and $45 \%$ and $87 \%$ for CIN 1 , respectively. The specificity was calculated to be $95 \%$ for Pap test and $80 \%$ for the combined test. 
Table VII: Studies from literature about the polar probe

\begin{tabular}{|l|l|l|}
\hline & sensitivity & specificity \\
\hline $\begin{array}{l}\text { M. Coppleso et al. } \\
\text { 1994[9] }\end{array}$ & $\begin{array}{l}85 \% \text { CIN1-atypia } \\
90 \% \text { CIN2-CIN3 } \\
99 \% \text { Invasive cancer }\end{array}$ & $86-97 \%$ \\
\hline Singer A et al. * 1997[10] & $98 \%$ & $91 \%$ \\
\hline Singer A et al. 2003[7] & $\begin{array}{l}67 \%(\mathrm{CIN} 1) \\
70 \%(\mathrm{CIN} 2-3)\end{array}$ & $81 \%$ \\
\hline Abdul S et al. 2006 [11] & $74 \%(\mathrm{CIN2/3)}$ & $53 \%$ \\
\hline Pruski D et al. 2008[12] & $\begin{array}{l}53 \% \text { CIN (1-2) } \\
80 \% \text { CIN3 }\end{array}$ & $84 \%$ \\
\hline He Xiu-kui et al 2010 [13] & $32.2 \%$ & $96.7 \%$ \\
\hline Long S et al. 2013 [4] & $67.4 \%$ & $68.1 \%$ \\
\hline * Values for invasive cancer & &
\end{tabular}

In our study, as all patients included in the screening group did not have a histological diagnosis, the sensitivity and the specificity could not be calculated. Only the patients with an abnormal result of TruScreen were referred to colposcopy and gave biopsy specimens. PPV was $27 \%$ for TruScreen test, $16 \%$ for Pap test and $33 \%$ for colposcopy. In our study, there were 8 patients with abnormal cytological results, who underwent TruScreen test. When we compared these results, we observed that TruScreen gave a false negative result in 1 patient with HSIL. One patient with ASCUS and 1 patient with LSIL had not to biopsy result due to previously normal TruScreen result. However, despite the observation of abnormal cytological results obtained with TruScreen in 7 patients with biologically confirmed LSIL and 1 patient with biologically confirmed HSIL, the cytological analysis gave a false negative result in these patients. In two tests, different patient groups were diagnosed, and it is clearly observed that the combination of two tests will increase the accuracy rate of the screening.

Ultimately, the positivity rate of TruScreen was $31.9 \%$, and $27 \%$ of these patients would have histological HPV effect and other dysplasias. Seventy-three percent of the patients, who had abnormal results, would have undergone unnecessary colposcopy. In our study, the rate of chronic cervicitis was quite high (62.2\%). This may be explained by the fact that we enrolled all the patients in whom the transformation zone was visualized and who were found to be eligible for TruScreen to the screening.

When we evaluated TruScreen based on the tests performed in the literature, we found that it was at least as effective as the Pap test. Thus, a good sensitivity rate is important for diseases with low prevalence. As our study had a limited number of colposcopy facilities, and the test gave positive results at a rate of $1 / 3$, in this study, colposcopy was performed only in the patients with positive TruScreen result. As also seen in our study, histologic abnormality capturing is better with TruScreen compared to the Pap test. In 1438 patients, the prevalence of cytological abnormality detected with Pap test was $1.04 \%$ (15 patients), similarly to the prevalence published by Turkish Cervical Cancer and Cervical Cytology Study Group in 2009. In this study, Overall, the prevalence of cervical cytological abnormalities was $1.8 \%$; the prevalence of ASCUS, ASC-H, LSIL, HSIL, and AGC was $1.07 \%, 0.07 \%, 0.3 \%, 0.17 \%$, and $0.08 \%$, respectively ${ }^{14}$. However, this rate was given as $6.9 \%$ (ASCUS, 4.5\%; LSIL, 1.6\%; HSIL, $0.5 \%$; AGC, $0.3 \%$ ) in an American study that contained laboratory data obtained in $2000^{15}$. In our study, the patients who were screened using TruScreen showed a rate of histologic abnormality of $6.5 \%$ (54/819). In our study, based on the patients with histological diagnoses, Pap test gave a false negative result in 1 patient with a high-grade lesion (50\%; 1/2 patient) and in 7 patients with LSIL (0/7). TruScreen omitted high-grade lesion in 1 patient. However, as the number of the patients with normal TruScreen results in whom we performed colposcopy and biopsy is limited, it 
would not be right to compare TruScreen and Pap test in this point.

\section{CONCLUSION}

In our study, TruScreen was found to have a higher cervical dysplasia capturing rate compared to the Pap test. However, in the screening performed using TruScreen, the rate of colposcopy substantially increases, affecting the cost of the screening. Use of TruScreen alone is not a cost-effective method. Its combination with other tests would decrease the excessively high rate of colposcopy use and allow its use as a more efficient screening method. Conducting the studies for the use of TruScreen test combined with other tests rather than for its use alone seems to be more promising for the future.

\section{Ethics Committee Approval: Baskent University Hospital, Ethics Board (project number KA09/159)}

Declaration of Conflicting Interests: The authors declare that they have no conflict of interest.

Financial Disclosure: Financial support for this work was provided by Baskent University.

\section{REFERENCES}

1. Cancer, I.A.f.R.o., Globocan 2018: estimated cancer incidence, mortality and prevalence worldwide in 2018 http://gco.iarc.fr/today/explore

2. Mirili C., Yılmaz A., Bilici M., Tekin S.B. Long-Term Follow-Up Outcomes of Cervical Cancer Patients: A Single Center Experience from the East Anatolian Region of Turkey Dicle Med J 2019; 46 : 857-65.

3. Corneanu LM, Stanculescu D, Corneanu C. HPV and cervical squamous intraepithelial lesions: clinicopathological study. Rom J Morphol Embryol. 2011; 52: 89-94.

4. Long S, Lei W, Feng Y, Lv D, Cai Y, Yang P. The feasibilities of TruScreen for primary cervical cancer screening: a self-controlled study. Arch Gynecol Obstet. 2013; 288: 113-8.

5. American College of O, Gynecologists. ACOG Practice Bulletin No. 99: management of abnormal cervical cytology and histology. Obstet Gynecol. 2008; 112: 141944.

6. Gibb RK, Martens MG. The impact of liquid-based cytology in decreasing the incidence of cervical cancer. Rev Obstet Gynecol. 2011; 4: S2-S11.

7. Singer A, Coppleson M, Canfell K et all. A real time optoelectronic device as an adjunct to the Pap smear for cervical screening: a multicenter evaluation. Int J Gynecol Cancer. 2003; 13 :804-11.

8. Mould T A J, Q.S.C., Lovegrove J, Gallivan S, Singer A, The acceptability of cytological screening for cervical cancer compared to a new electronic screening device-the Polarprobe. Proceedings of the EUROGIN Third International Congress, 1997. European Research Organization on Genital Infection and Neoplasia, 1997 (March 24-27).

9. Coppleson M, Reid BL, Skladnev VN, Dalrymple JC. An electronic approach to the detection of pre-cancer and cancer of the uterine cervix: a preliminary evaluation of Polarprobe. Int J Gynecol Cancer. 1994; 4: 79-83.

10. Singer, A., Clinical experience with the usage of the Polarprobe. Proceedings of the EUROGIN Third International Congress, 1997. European Research Organization on Genital Infection and Neoplasia, 1997( 1997 ): p. March 24-27.

11. Abdul S, Brown BH, Milnes P, Tidy JA. The use of electrical impedance spectroscopy in the detection of cervical intraepithelial neoplasia. Int J Gynecol Cancer. 2006; 16: 1823-32.

12. Pruski D, Kedzia W, Przybylski M, et all. Assesment of real optoelectronic method in the detection of cervical intraepithelial neoplasia. Ginekol Pol. 2008; 79: 342-6.

13. He XK, Luo XP, Mao LZ, et all. An optoelectronic cervical cancer screening system for screening cervical cancer: comparison with cervical cytology. Nan Fang Yi Ke Da Xue Xue Bao. 2010; 30: 2304-6.

14. Turkish Cervical C, Cervical Cytology Research G. Prevalence of cervical cytological abnormalities in Turkey. Int J Gynaecol Obstet. 2009; 106: 206-9.

15. Davey DD, Woodhouse S, Styer P, Stastny J, Mody D. Atypical epithelial cells and specimen adequacy: current laboratory practices of participants in the college of American pathologists interlaboratory comparison program in cervicovaginal cytology. Arch Pathol Lab Med. 2000; 124: 203-11. 